\title{
Dismantling of the VVR-S Nuclear Research Reactor Vessels
}

\author{
R. Deju, D. Gurau, A. Zorliu and M. Mincu* \\ Horia Hulubei National Institute for Physics and Nuclear Engineering, Bucharest-Magurele, 077125, Romania

\begin{abstract}
Starting with 2010 and until 2020, the VVR-S nuclear research reactor from Magurele, Romania, is in the decommissioning process. The reactor aluminum assembly contains the internal vessel which represent the main component of the reactor. In order to identify the optimum technological methods of dismantling and cutting, the initial radiological characterization of the reactor vessel was conducted. Modern methods like plasma jet, diamond wire cutting, shredding with a Brokk 160 demolition robot were used in this process. Safety aspects for optimizing radiation protection of operating personnel were analyzed and innovative solutions were identified. The lessons learned from the reactor vessels dismantling were presented.
\end{abstract}

DOI: 10.12693/APhysPolA.134.300

PACS/topics: decommissioning, dismantling, reactor vessel, radiological characterization and monitoring

\section{Introduction}

Horia Hulubei National Institute for Physics and Nuclear Engineering (IFIN-HH) from Magurele, Romania, is the owner of the VVR-S nuclear research reactor, cooled and moderated with distilled water, which was commissioned in 1957, shut down in 1997 and permanently closed in 2002 [1]. The purpose of the reactor was the research in nuclear physics and radioisotopes production. Starting with 1957 and until December 1983, the reactor has operated using low-enriched nuclear fuel (10 wt\% $\left.{ }^{235} \mathrm{U}\right)$, and since January 1984, highly enriched fuel (36 wt\% $\left.{ }^{235} \mathrm{U}\right)$. According to the project documentation, the main functions and services provided after the commissioning of the reactor were: (i) use of the neutron flux for research in physics, biophysics, biochemistry and radiochemistry, (ii) production of radioisotope used in industry and medicine, (iii) irradiation for shortening switching diodes, (iv) silicon doping for the electronics industry, (v) calibration of the control equipment of the reactor in neutron field and in neutron and gamma radiation field, (vi) maintaining in working order the two neutron density national standards of medium and high energy, (vii) use of the internal column with high thermal neutron flux for some special radiation.

The dismantling and decommissioning of a nuclear research reactor, is an administrative and technical process to the point that it no longer requires measurements for radiation protection $[2,3]$. A wide range of nuclear facilities have been decommissioned until now [4-8], and their number is expected to grow.

This paper propose to review the technology applied and the experience gained during the reactor vessels decommissioning. The dismantling of the reactor vessels of the VVR-S reactor is described.

*corresponding author; e-mail: monica.mincu@nipne.ro

\section{Description of the reactor vessels}

The reactor vessels assembly (Fig. 1a) contain three components made from SAV-1 aluminum alloy with $97.6 \div 98.6 \% \mathrm{Al}, 0.7 \div 1.2 \% \mathrm{Si}, 0.45 \div 0.9 \% \mathrm{Mg}, 0.012 \% \mathrm{Cu}$, $0.03 \% \mathrm{Zn}, 0.2 \% \mathrm{Fe}, 0.3 \% \mathrm{Ni}, 0.01 \% \mathrm{Mn}$ chemical composition. The outer vessel of the reactor is a cylindrical vessel with a curved bottom, a diameter of $2.24 \mathrm{~m}$, a height of $5.7 \mathrm{~m}$ and a thickness of $1.6 \mathrm{~cm}$. This has the role of biological protection in which the experimental horizontal channels are placed.
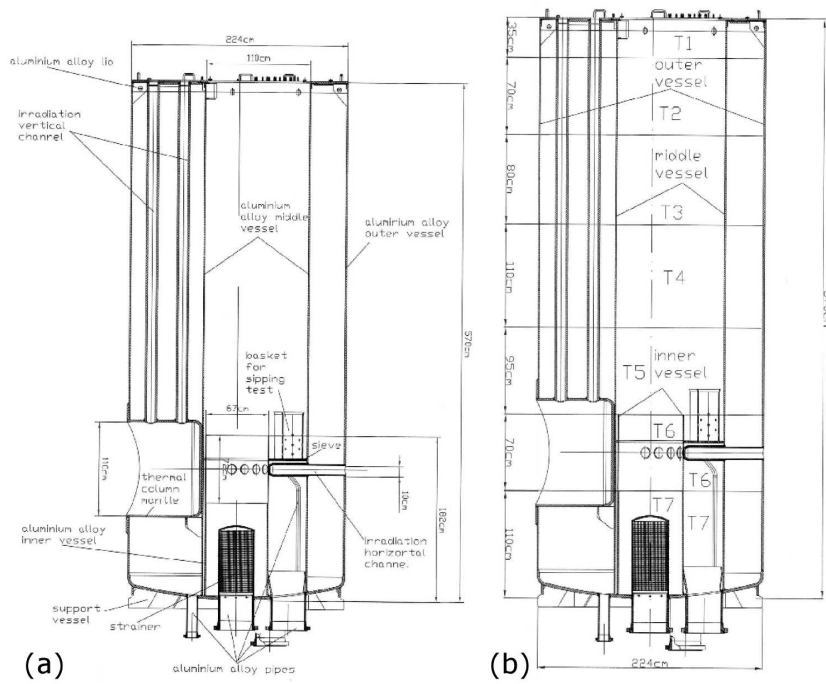

Fig. 1. VVR-S reactor block: (a) cross-section, (b) $\mathrm{T} 1 \div \mathrm{T} 5$ sections (outer and middle vessel) and T6, T7 sections (outer, middle and inner vessel).

Inside the outer vessel of the reactor, there are two additional cylindrical vessels made from the same aluminum alloy with a thickness of $1.2 \mathrm{~cm}$. The middle vessel has a diameter of $1.1 \mathrm{~m}$ and a height of $5.7 \mathrm{~m}$ and has the role of cooling the reactor and contain the ionization chambers and the transport channel. The third vessel is the inner vessel which represents the main component 
of the reactor where the active zone of the reactor, the control and protection rods, and the irradiation channels are placed. This vessel has a diameter of $0.67 \mathrm{~m}$ and a height of $1.82 \mathrm{~m}$.

Between the middle and the inner vessels a sieve is placed to distribute uniformly the primary coolant that comes from the heat exchangers and to prevent intrusion of foreign bodies in the active area. Both the outer and the middle vessels are provided at the top with a lid of SAV-1 aluminum alloy.

In the middle vessel there is an overflow pipe through which water flows in the drainage system when the fixed level is exceeded. Around the active area are present: (i) 9 experimental horizontal channels (3 channels with $6 \mathrm{~cm}$ in diameter and 6 channels with $10 \mathrm{~cm}$ in diameter), (ii) a hole with $1.116 \mathrm{~m}$ diameter where the thermal column is introduced and contain 4 vertical channels ( 2 placed in water of the biological protection and 2 in the concrete), (iii) 3 channels placed in the middle and the inner vessel (2 channels with $4.5 \mathrm{~cm}$ in diameter and 1 channel with $7 \mathrm{~cm}$ in diameter) used to transport the irradiated samples from the reactor core to the hot chambers, (iv) 1 channel with $26 \mathrm{~cm}$ in diameter used to transport the spent fuel in the cooling pond. In the space between the spent fuel assemblies and the separator are placed 16 vertical experimental channels from which 4 channels are removable. Also, in the concrete protection, in the axial position there are placed different vertical channels: (i) 3 for biological experiments, (ii) 4 for monitoring, (iii) 1 for keeping the road of the loading mechanism of the active zone, (iv) 7 for keeping the ionization chambers and the control and protection rods, (v) 7 for storage the plugs of the ionization chambers and the control and protection rods, (vi) 2 experimental channels of thermal column, (vii) 2 for storage the plugs of the experimental channels of thermal column, (viii) 2 for the plugs of the two vertical channels from the thermal column placed in the central part of the reactor.

\section{Radiological characterization}

In order to achieve a detailed radiological characterization of the reactor block, samples need to be taken. Before this, many dose rate measurements were made to evaluate the highest point of the activated areas. An initial dose rate scanning was made using Thermo Scientific ${ }^{\mathrm{TM}} \mathrm{FHZ}$ 691-10 probe, especially suited to detect dose rate increases as small as 3 percent at normal background within a measuring time of one minute. The measurements were made on the inside part of the outer aluminum alloy vessel, at contact, in the perpendicular position to the thermal column. Due to the sieve placed between the middle and the inner vessels, supplementary scanning measurements were made from the room under the reactor block, inserting the detector inside the cooling pipes up to contact with the bottom of the sieve. As was expected, the highest value of dose rate that was registered, was next to the active area.
To evaluate the activation degree, samples were taken from the reactor vessels made from aluminum alloy and from cast iron rings. The core drilling technique samples was used for this purpose. Two areas were chosen for core drilling in horizontal direction, across the axis of the reactor vessel (Fig. 2).

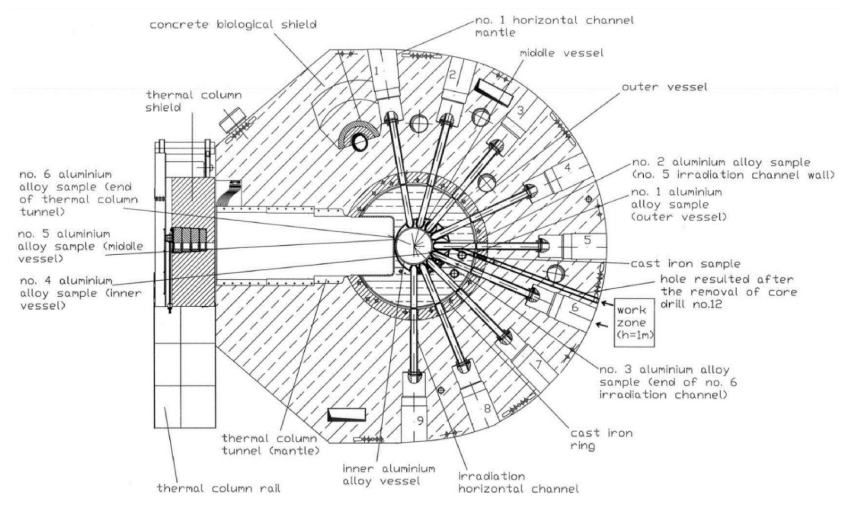

Fig. 2. Reactor block - drilling points in cast iron ring and aluminum alloy vessels.

Area no. 1 was chosen between the horizontal channels no. 5 and no. 6 , at $1 \mathrm{~m}$ above the floor. The core drilling was done through the core drilling made in a previous study in the heavy concrete biological protection of the reactor. Area no. 2 was chosen to be made on the horizontal channel no. 6 at $1 \mathrm{~m}$ above the floor, directly through the irradiation channel. The core drilling operations were made with Hilti DD200 heavy-duty diamond drilling system for rig-based coring in medium-to-large diameters. Water was used as a coolant. 9 detachable extension tubes with $5 \mathrm{~cm}$ in diameter (exterior) and diamond segments with the size of $50 \times 38 \times 3 \mathrm{~mm}^{3}$ were used to extract the aluminum alloy and cast iron samples. Each sample was identified by a code which corresponds to the place where it was taken. All the samples were collected on a stainless steel tray with lead shielding all around to protect the workers. The core drilling operations led to the identification of the activity level of the samples taken from the steel iron ring of the reactor, and of the SAV-1 aluminum alloy samples taken from the outer, middle and inner reactor vessels.

From the area no. 1, samples of steel iron, steel iron fillings, water, aluminum alloy and paint samples were collected. One core drilling of steel iron with a length of $20.5 \mathrm{~cm}$ and a diameter of $3.6 \mathrm{~cm}$ was collected from the steel iron ring protection of the reactor. To evaluate the activity by gamma-ray spectrometry and the radioactivity distribution, the core drilling was cut in ten small samples using the band saw machine BMSY 440 CGH. Samples of steel iron fillings and water resulted from the mechanical cutting of the steel iron core drilling, aluminum alloy from the outer vessel and from the irradiation channel no. 5, were measured and analyzed.

From the area no. 2, four samples of aluminum alloy were collected. Each one from the end of the irradiation 
channel no. 6 , the wall of the inner vessel, the wall of the middle vessel and the end of the tunnel of the thermal column. The sample of paint was collected by scraping the face of the sample collected from the outer aluminum alloy vessel.

Dosimetry measurements were made on each sample collected in the view of the working radiation protection. The values registered were from 2 to $40 \mu \mathrm{Sv} / \mathrm{h}$ for steel iron samples and from 1 to $210 \mu \mathrm{Sv} / \mathrm{h}$ for aluminum alloy samples, starting from outside to inside for both type of samples.

During the core drilling activities, couple of dosimetry equipments were used for monitor the area of the workers, such as: FHT 6020 Area Monitor Display and Alarms, AMS-4 Beta Air Monitor and portable dose rate monitor LB 123 D-H10 for measurement of the ambient dose and ambient dose rate equivalent $\mathrm{H}^{*}(10)$.

\subsection{Dose rate measurements}

The equipments used for dose rate measurements were: a FH 40 TG telescopic probe or a FHZ 612-10 gamma dose rate detector connected to a FH 40 G multi-purpose digital survey meter. The measurements were performed in a vertical plan, inside the reactor vessel axis and under the reactor block, where dose rate values were registered in the range from $70 \mu \mathrm{Sv} / \mathrm{h}$ and $9 \mathrm{mSv} / \mathrm{h}$.

Results obtained for aluminum alloy samples
Dose rate measurement were also performed in the area between the outer and the middle vessels, in the area of the horizontal irradiation channels. Here, the values registered were between $600 \mu \mathrm{Sv} / \mathrm{h}$ and $13 \mathrm{mSv} / \mathrm{h}$.

Dosimetric measurements were performed, using the thermoluminescent dosimeter (TLD). A number of 25 pieces of TLD were used for this procedure, from which one was used as area control being placed at the top of the reactor vessels. The rest of 24 TLD cassettes have left inside the internal vessel on three rows ( 8 cassettes on one row), at different depth $(+1 \mathrm{~m}$ which corresponded beside the active area, $+1.5 \mathrm{~m}$ and $+0.5 \mathrm{~m})$. The measurements were perform for $1 \mathrm{~h}$ and the values were between $1.37 \mathrm{mSv} / \mathrm{h}$ and $16.62 \mathrm{mSv} / \mathrm{h}$.

\subsection{Gamma-ray spectrometry results}

The gamma-ray spectrometry measurements were performed using a gamma-ray spectrometry system with HPGe detector, type GEM60P4-95, a DSPEC jr.2.0- Digital Multichannel Analyzer, a lead castle and GammaVision-32 software. For aluminum alloy samples, ${ }^{152} \mathrm{Eu},{ }^{154} \mathrm{Eu},{ }^{155} \mathrm{Eu},{ }^{60} \mathrm{Co},{ }^{137} \mathrm{Cs}$ radionuclides have been detected. The specific activity results are presented in Table I. The uncertainties were around $26 \%$ for $1 \sigma$.

\begin{tabular}{l|c|c|c|c|c}
\hline \hline \multirow{2}{*}{ Location } & \multicolumn{3}{|c}{$\Lambda$ sp. $[\mathrm{Bq} / \mathrm{g}]$} \\
\cline { 2 - 6 } & ${ }^{152} \mathrm{Eu}$ & ${ }^{154} \mathrm{Eu}$ & ${ }^{155} \mathrm{Eu}$ & ${ }^{60} \mathrm{Co}$ & ${ }^{137} \mathrm{Cs}$ \\
\hline outer vessel & 0.933 & 0.157 & - & 2.36 & - \\
wall of the irradiation channel no. 5 & $1.81 \times 10^{2}$ & 12.8 & - & $2.57 \times 10^{2}$ & 3.56 \\
end of the irradiation channel no. 6 & - & $1.19 \times 10^{3}$ & $2.29 \times 10^{2}$ & $1.17 \times 10^{4}$ & $1.22 \times 10^{2}$ \\
wall of the inner vessel & - & $1.42 \times 10^{3}$ & $3.37 \times 10^{2}$ & $1.78 \times 10^{4}$ & $1.93 \times 10^{2}$ \\
wall of the middle vessel & - & $8.61 \times 10^{2}$ & $1.70 \times 10^{2}$ & $1.61 \mathrm{E} \times 10^{4}$ & $1.15 \mathrm{E} \times 10^{2}$ \\
end of the thermal column tunnel & 14.2 & $4.02 \times 10^{2}$ & 71.3 & $6.64 \times 10^{3}$ & 58.1
\end{tabular}

For steel iron samples, ${ }^{60} \mathrm{Co}$ was the identified radionuclide. The samples were measured on both sides to get a homogeny distribution of the activity in the sample. The results are presented in Table II.

Results obtained for steel iron samples

TABLE II

\begin{tabular}{c|c|c}
\hline \hline \multirow{2}{*}{ Sample } & $\Lambda$ sp. $[\mathrm{Bq} / \mathrm{g}]$ & \multirow{2}{*}{$u[\%](1 \sigma)$} \\
\cline { 2 - 2 } & ${ }^{60} \mathrm{Co}$ & 30.0 \\
s1 & 58.5 & 10.0 \\
s2 & 50.4 & 10.0 \\
s3 & 41.3 & 10.0 \\
s4 & 40.0 & 10.0 \\
s5 & 46.3 & 10.0 \\
s6 & 60.0 & 10.0 \\
s7 & $1.11 \times 10^{2}$ & 10.0 \\
s8 & $2.68 \times 10^{2}$ & 10.0 \\
s9 & $5.24 \times 10^{2}$ & 30.0 \\
s10 & $8.59 \times 10^{2}$ &
\end{tabular}

The uncertainties of the first and the last samples were bigger because of the elliptical shape of one side of the specific samples. This is due to the angle in which the core drilling was done.

During the coring process, the water is pumped through the core to provide cooling at the drill face and to flush away the loose material. A sample from this water was measured and analyses by gamma-ray spectrometry and the results are presented in Table III.

The result obtained for ${ }^{60} \mathrm{Co}$ identified in steel iron filings is under the release level. The same situation is also for the paint samples, where ${ }^{60} \mathrm{Co},{ }^{137} \mathrm{Cs}$ and ${ }^{152} \mathrm{Eu}$ radionuclides were identified.

TABLE III

Results obtained for water and steel iron filings and paint

\begin{tabular}{l|c|c|c|c}
\hline \hline \multirow{2}{*}{ Type of sample } & \multirow{2}{*}{ Quantity } & \multicolumn{3}{|c}{$\Lambda[\mathrm{Bq}]$} \\
\cline { 3 - 5 } & & ${ }^{152} \mathrm{Eu}$ & ${ }^{60} \mathrm{Co}$ & ${ }^{137} \mathrm{Cs}$ \\
\hline water & $476 \mathrm{ml}$ & - & 10.0 & - \\
steel iron filings & $64.55 \mathrm{~g}$ & - & $5.12 \times 10^{3}$ & - \\
paint & $29.77 \mathrm{~g}$ & $<2.94$ & 25.0 & 4.18
\end{tabular}


Still, even after 20 years form the shutdown of the reactor, ${ }^{60} \mathrm{Co},{ }^{137} \mathrm{Cs},{ }^{152} \mathrm{Eu},{ }^{154} \mathrm{Eu}$ and ${ }^{155} \mathrm{Eu}$ remain the main radionuclides present in the aluminum alloy vessel and the still iron rings. This is due the life time of the radionuclides and the high activity of this systems.

For the purpose of the dismantling activities, it was established that the worker will not exceed the dose rate of $10 \mu \mathrm{Sv} / \mathrm{h}$.

\section{The dismantling of the reactor vessels}

The support between the outer vessel and the iron plate that were placed under the reactor, have been removed using plasma cutting technique. This was done to allow the movement of reactor vessel assembly (Fig. 1b).

The aluminum alloy lid from the upper side of the reactor, between the outer and middle vessel, was removed from the clamping screws, and then, using the crane, was evacuated to the primary measurements and cutting area. After this, the centering profiles of the outer and middle vessel and the funnel of the channel between the reactor and the cooling pond, were cut.

To manage properly these activities, the reactor vessels have been marked in 7 sections (T1 to T7) with height from 35 to $110 \mathrm{~cm}$ (Fig. 1b).

Four equipments have been used for cutting: (i) Hypertherm Powermax 105 plasma cutting system with cutting torch and remote lance for cutting from remote locations, (ii) Auto-Picle-P plasma pipe cutting machine designed to use plasma for high speed cutting of carbon steel, stainless steel, aluminum and other metals, (iii) Braun BWS 12-S fully automatic diamond wire cutting device, which does not use a cooling agent and was developed specially for aluminum alloy SAV-1 (resistant to temperature of $100^{\circ} \mathrm{C}$ ), (iv) Brokk 160 remote controlled demolition robot.

\subsection{Dismantling the reactor vessels sections}

This section describes the actions done and the procedures followed to dismantle the aluminum alloy reactor vessels.

For the dismantling of the T1 section of outer and middle vessels, the reactor vessels have been anchored and pulled up about $55 \mathrm{~cm}$ using the bridge crane hook (Fig. 3a). Four holes have been made on one side and the other of the outer vessel, using the plasma jet, for the introduction of two metal profiles (U-shaped of $100 \mathrm{~mm}$ ) to sustain the reactor vessels. In this stage, the bridge crane hook could be released. The Auto-Picle-P plasma pipe cutting machine was assembled on the outer vessel and it was attached to plasma cutting torch. The Hypertherm Powermax 105 plasma cutting system have been turn on and began the cutting of the outer vessel from remote locations. Thus, the cart with the torch in operation has moved on the guide rail making a narrow cut. This system has the advantage that can be operated by remote control from distance and thus the radiological exposure of the operating personnel was minimal. The vertical channels between the outer and the middle vessels, the T1 section of the middle vessel and the vertical channels within the middle vessel, were cut with the Hypertherm Powermax 105 plasma cutting system with cutting torch and remote lance for cutting, from remote locations.
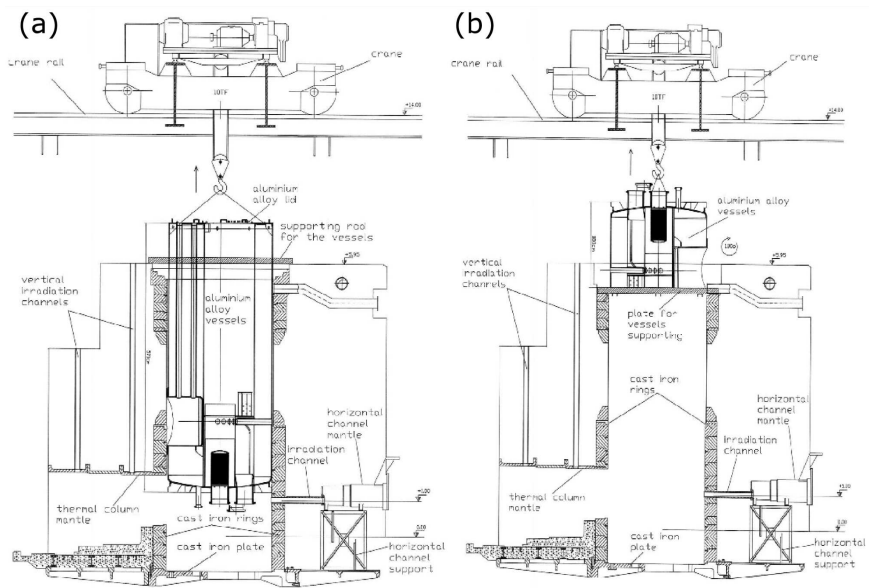

Fig. 3. Winding a cutting upper part of reactor vessel: (a) T1 $\div \mathrm{T} 5$ sections (outer and middle vessel), (b) T6, T7 sections (outer, middle and inner vessel).

After the T1 section was finished, the same procedure was followed for $\mathrm{T} 2$ section of outer and middle vessels. Two metal profiles were introduced in the outer vessel, and using the bridge crane hook, the aluminum alloy assembly was pulled up about $90 \mathrm{~cm}$ to prepare the cutting of a ring of $70 \mathrm{~cm}$, specific to the T2 section. The cutting activities were followed as before for the second section.

After the T2 section was finished for cutting and removed from the reactor area, the aluminum alloy assembly was anchored in the bridge crane hook and pulled up about $100 \mathrm{~cm}$ to prepare the cutting of the 3rd section. The T3 section of the outer and the middle vessels was about $80 \mathrm{~cm}$. The cutting of the outer vessel was realized for a quarter using the Auto-Picle-P plasma pipe cutting machine, and then, the cutting was done by the workers with cutting torch. The middle vessel and the vertical channels have been cut with the Hypertherm Powermax 105 plasma cutting system from remote location. When the operation for the dismantling and the evacuation of the T3 section were finished, the remaining part of the aluminum alloy assembly was anchored with the bridge crane hook and pulled up about $130 \mathrm{~cm}$, and then fixed using the metal profiles (Fig. 3a). For the cutting of the $\mathrm{T} 4$ section $(110 \mathrm{~cm})$, the next procedure have been done: (i) the outer vessel was cut with the Hypertherm Powermax 105 plasma cutting system from remote location, (ii) the vertical channels were cut using the Brokk 160 remote controlled demolition robot equipped with metal cutting scissors, (iii) the middle vessel was cut with the Hypertherm Powermax 105 plasma cutting system from remote location. 
When the T4 section was finished, T5 section was pulled about $115 \mathrm{~cm}$, to cut $95 \mathrm{~cm}$. In this area, the dose rate was higher and the workers was required to perform the cut actions from distance. The cutting were performed using the diamond wire cutting device. The equipment was positioned on the reactor bridge, at $4 \mathrm{~m}$ from the reactor vessels. Two PRECON concrete blocks $\left(60 \times 60 \times 80 \mathrm{~cm}^{3}\right)$ were used to protect the workers. The monitoring and controlling of the cutting device was done from a distance of approximately $12 \mathrm{~m}$. The cutting of the outer and middle vessels, and of the vertical channels, was done with the Braun device with diamond wire from distance. In the case of the $\mathrm{T} 6$ and $\mathrm{T} 7$ sections, for a minimal exposure of the operating personnel, it was necessary to evacuate the inferior remaining part of the vessel from the reactor block (the active area). The vessel was placed of the reactor hall floor and rotated $180^{\circ}$ (Fig. 3b). In this stage, a support made from steel profiles (U-shape of $80 \mathrm{~mm}$ and I-shape of $100 \mathrm{~mm}$ ) was placed of the reactor block on which an aluminum plate with $0.5 \mathrm{~cm}$ thickness was mounted. The rotated vessel was transported using the bridge crane on the aluminum place from the reactor block. The cutting of the T7 section (outer and middle vessels and the vertical channels) was done using the Braun device with diamond wire from distance.

The cylindrical sections of the T1-T5 sections (outer and middle vessels and the vertical channels) and the T7 section (outer, middle and inner vessels and the vertical channels) were evacuated in the preliminary measurements and cutting area, where these have been dismantled/cut with plasma jet in small pieces, easy to handle and to be fitted in $220 \mathrm{l}$ drums. The plasma jet technique was chosen, because the Proma band saw available in the reactor hall does not allow to put large cylindrical sections on the cutting table. The T6 sections of the outer, middle and inner vessels were evacuated together, since in the central area the horizontal channels were placed and welded on the vessels. The dimension of $70 \mathrm{~cm}$ was chosen for the T6 section, because this part has the higher activity and this section will be transferred in one basin of the intermediary storage.

\subsection{The radiological monitoring during the reactor vessels dismantling}

The radiological monitoring includes: (i) the dose rate measurements, (ii) evaluation of the activity concentration in the air in work areas, (iii) sampling of the components during dismantling, (iv) measurements of external radiation exposure of the personnel, (v) control of internal exposure of the personnel. The external exposure is in the main path because the internal exposure during the dismantling is considered to be minimal since the release of aerosols is smaller and multiple actions are taken into account to protect against radiation. The control for human body is used to determine the incorporation of gamma radionuclides for personnel, from the beginning and the end of their work.

\subsection{Safety precautions regarding radiation protection}

Due to the high activity of the active area, the cutting of the reactor vessels could led to some technical difficulties and radiological risks. It is therefore necessary to take suitable measures for radiological protection before work, such as: (i) use of mobile lead shield with dimensions of $50 \times 150 \mathrm{~cm}^{2}$ and $0.5 \mathrm{~cm}$ thickness, (ii) positioning in the working area in addition to the ventilation systems associated to the reactor hall of two PFB-1600 cart mounted HEPA filtration systems, (iii) the establishment of the minimal distance where the operator can work and the maximum duration of the working time, (iv) decontamination of the components, (v) properly equipping of operators from work area, including protective lead apron and masks for radioactive aerosols.

\subsection{ALARA performance during the dismantling actions}

Every reasonable effort was done to maintain exposures to ionizing radiation as far below the dose limits as practical. The ALARA monitoring was done watching to the following information: (i) the external dose rate received on a work permit/ team work/ person, daily available in reports, (ii) comparison between the estimated and real collective dose, (iii) framing in the set targets for ALARA indicators. In Table IV there are presented the stochastic health effects of low levels of ionizing radiation on the human body during the dismantling activities. The equivalent dose, Hp (10), was provided by the Saphydose Gamma isotropic electronic dosimeter.

A1 - scanning under the reactor, A2 - pulled up of the reactor vessel, cutting and dose rate measurements, A3 - cutting and dose rate measurements of the reactor vessels and vertical channels, A4 - dose rate measurements when the vessel assembly is pulled up, making holes for fixing the support, cutting of the outer and middle vessels, A5 - scanning the inner vessel, A6 - instalation and setup of the diamond wire cutting device, A7 - vessel cutting with diamond wire and plasma jet, transferring the cut sections to the intermediary storage.

During the working time, the dose rate not exceeded $0.04 \mathrm{mSv} / \mathrm{h}$ per man. In Table $\mathrm{V}$ there are presented the internal and external irradiation values of the mechanical and dosimetry operators.

The collective dose evaluated for the operator personnel was of $0.795 \mathrm{mSv}$ man. This was for the 7 mechanical operators that were involved in the dismantling of the reactor vessel assembly and the radioactive waste handling, and for the 3 dosimetry operators, for an effective work time of $54 \mathrm{~h}$. For the rest of the decommissioning team, which work outside the controlled area, there was no radiation exposure. The value of the measured collective dose was acceptable in comparison with the estimated collective dose $<1 \mathrm{mSv}$ man. In accordance with the exclusion requirements of the Radiological Safety Fundamental Regulations NSR-01, of the National Commission for Nuclear Activities Control (CNCAN), the annual total dose for one work operator is of $20 \mathrm{mSv}$ [9]. 


\begin{tabular}{|c|c|c|c|c|c|c|c|c|c|c|c|}
\hline \multirow{3}{*}{ Work period } & \multirow{3}{*}{ Activity } & \multicolumn{10}{|c|}{$\mathrm{Hp}(10) \times 10^{-1}[\mathrm{mSv}]$} \\
\hline & & \multicolumn{7}{|c|}{ Mechanical operator } & \multicolumn{3}{|c|}{ Dosimetry operator } \\
\hline & & no. 1 & no. 2 & no. 3 & no. 4 & no. 5 & no. 6 & no. 7 & no. 1 & no. 2 & no. 3 \\
\hline 18 April & A1 & 0.06 & - & - & - & - & - & - & - & - & 0.05 \\
\hline $19 \div 29$ April & A2 & 0.32 & 0.14 & 0.20 & 0.14 & 0.05 & 0.08 & - & 0.04 & 0.04 & 0.10 \\
\hline $03 \div 31$ May & A3 & 0.31 & 0.40 & 0.05 & 0.31 & 0.07 & 0.09 & - & 0.10 & 0.01 & 0.13 \\
\hline $06 \div 29$ June & A4 & 0.53 & 0.30 & 0.12 & 0.14 & 0.18 & 0.09 & 0.02 & 0.21 & 0.11 & 0.10 \\
\hline $01 \div 04$ July & A5 & 0.05 & - & - & - & 0.01 & 0.01 & 0.01 & 0.01 & - & 0.18 \\
\hline $03 \div 31$ August & A6 & 0.86 & 0.75 & 0.46 & 0.23 & 0.14 & 0.04 & 0.17 & 0.08 & 0.19 & 0.22 \\
\hline $01 \div 17$ September & A7 & - & 0.48 & 0.40 & 0.11 & 0.11 & 0.17 & 0.40 & 0.36 & 0.20 & 0.13 \\
\hline Total & & 2.13 & 2.07 & 1.23 & 0.93 & 0.56 & 0.48 & 0.60 & 0.80 & 0.55 & 0.91 \\
\hline
\end{tabular}

Radiological exposure of the operator personnel

TABLE V

\begin{tabular}{|c|c|c|c|c|c|c|c|c|c|}
\hline \multirow{3}{*}{\multicolumn{2}{|c|}{ Operator }} & \multicolumn{8}{|c|}{ Irradiation [mSv] } \\
\hline & & \multicolumn{6}{|c|}{ External $^{a}$} & \multirow{2}{*}{ Internal $^{b}$} & \multirow{2}{*}{ Total } \\
\hline & & April & May & June & July & August & September & & \\
\hline \multirow{7}{*}{ Mechanical } & no.1 & 0.11 & 0.12 & 0.23 & 0.11 & 0.21 & 0.12 & 0.047 & 0.947 \\
\hline & no. 2 & 0.13 & 0.12 & 0.11 & 0.11 & 0.16 & 0.14 & 0.063 & 0.833 \\
\hline & no. 3 & 0.11 & 0.12 & 0.11 & 0.11 & 0.17 & 0.14 & 0.073 & 0.833 \\
\hline & no. 4 & 0.11 & 0.12 & 0.12 & 0.12 & 0.14 & 0.12 & 0.058 & 0.788 \\
\hline & no. 5 & 0.11 & 0.11 & 0.11 & 0.11 & 0.11 & 0.11 & 0.063 & 0.723 \\
\hline & no. 6 & 0.12 & 0.12 & 0.12 & 0.12 & 0.11 & 0.12 & 0.069 & 0.779 \\
\hline & no. 7 & 0.11 & 0.11 & 0.11 & 0.11 & 0.11 & 0.11 & 0.072 & 0.732 \\
\hline \multirow{3}{*}{ Dosimetry } & no.1 & 0.11 & 0.12 & 0.11 & 0.11 & 0.10 & 0.11 & 0.076 & 0.736 \\
\hline & no. 2 & 0.12 & 0.12 & 0.11 & 0.11 & 0.11 & 0.14 & 0.080 & 0.790 \\
\hline & no. 3 & 0.11 & 0.12 & 0.14 & 0.11 & 0.13 & 0.11 & 0.065 & 0.785 \\
\hline
\end{tabular}

${ }^{a}$ thermoluminescent dosimeter (TLD), ${ }^{b}$ personnel measurements

\subsection{Waste resulted}

The outer vessel presented on the external surface a layer of paint for protection which was contaminated. It has been attempted decontamination of each section of the aluminum alloy vessels with the following solutions: (i) DeconGel 1101, (ii) Super decapant, (iii) $10 \%$ citric acid, (iv) ethyl alcohol. The tests revealed that for this specific case, the best results have been obtained with the Super decapant.

From the reactor vessels, a quantity of $3560 \mathrm{~kg}$ of SAV1 aluminum alloy were cut and dismantled as follows: (i) $2120 \mathrm{~kg}$ were contaminated and activated and have been placed in 15 cylindrical drums of $220 \mathrm{l}$ for intermediary storage, (ii) $460 \mathrm{~kg}$ from the T6 section, have been placed in one basin of the intermediary storage, (iii) $980 \mathrm{~kg}$ from the outer vessel have been decontaminated and released under the authorization. If the dose rate at the wall of the drum do not meet the criteria for storage in the intermediary storage, then the drums (4 pieces) are placed in $420 \mathrm{l}$ EcolRAD containers.

\section{Experience gained and lessons learned}

The specific differences between the cutting methods recommend them for specific use. Besides advan- tages, each cutting method has drawbacks and limitations. From the cut and dismantling experience of the reactor vessels of the VVR-S nuclear research reactor from Magurele, Romania, the most effective equipment to cut the aluminum alloy vessels and the vertical channels, was the Braun device with diamond wire, for dry cutting. This is because the cuts were made in a shortest time than the other methods. Thus, the exposure to the ionizing radiation of the operator personnel was minimal. In the case of the cutting with diamond wire, to prevent the cut closing and the wire locking, wedges need to be used.

The operations for installation and dismantling of the Auto-Picle-P plasma pipe cutting machine was carried out with difficulty. Thus, the long working time spent near the reactor vessels assembly for assembling/disassembling the equipment was considered to be unjustified. The cutting operations were perform using two techniques: the plasma cutting was optimal to cut the reactor vessels in rings ( $\mathrm{T} 1 \div \mathrm{T} 7$ sections) and the fully automatic wall saw developed specially for aluminum was used to cut each $\mathrm{T}$ sections in small pieces. To achieve a proper cut (with puncture) of the aluminum walls, the distance between the operator and the cutting item need to be minimal. 
The Brokk 160 remote controlled demolition robot equipped with metal cutting scissors was used unsuccessfully in the cutting process of the vertical channels of the reactor. At the end of the cutting process of each channel, the robot scissors locks and crushed the channel.

After dismantling actions of the reactor vessels, useful lessons can be learned for future decommissioning projects of nuclear installations. The operator personnel must be trained and experienced, factor of maximum importance in the decommissioning operations. The people need to be trained continuously and repetitively with the provisions of applicable procedures. Training exercises can be made in advance to learn skills and abilities specific for dismantling. It is important to take into account all the radiological and non-radiological risks, before starting the decommissioning activities. To plan properly the decommissioning process, the radiological characterization of the reactor vessels, in this case, needs to be made with indirect analysis, and direct measurements of samples using gamma-ray spectrometry. The radiological characterization is the most important step to ensure the success of the decommissioning project. Even from the final shutdown of the reactor, periodically, the characterization needs to be updated taking into account the characteristics of the radionuclides. The dismantling operations must be clearly identified broken down into activities and stages. The experiences gain on one stage need to be learned before starting the next step. The dismantling method need to be chosen taking into account: (i) type of the material, (ii) dimensions of the components, (iii) level of contamination, (iv) need for radiological measurements, (v) cutting equipments available, (vi) cutting speed. Should avoid the cutting methods for which the installation and adjustment time for equipment cutting is high which can increase the dose received by the operating personnel.

It is important to notice that: (i) the decommissioning takes place in the form of nonrepetitive activities in a permanently changing environment, (ii) with the progress of decommissioning project, the radiological risk is reduced, while industrial risk increases. The "overprotection syndrome" regarding the contamination should be avoided. Depending on the specific project, the actions can be flexible and adopted to the real risk expected of the individual and collective protections.

\section{Acknowledgments}

This work was supported by the Romanian National Authority for Scientific Research, CNDI-UEFISCDI, in the framework of $16420301 / 2016$ national project.

The authors thanks to the decommissioning team and special to Argatu Laurentiu and Ionel Stoian for the technical support offered to publish this paper.

\section{References}

[1] R. Deju, I. Iorga, D. Gurau, Acta Phys. Pol. A 131, $82(2017)$.

[2] Yu.N. Lobach, M.T. Cross, Nucl. Eng. Des. 266, 155 (2014).

[3] Yu.N. Lobach, G. Toth, Nucl. Eng. Des. 258, 184 (2013).

[4] C. Cooke, H. Spann, in: Annual Waste Management Symp. (WM2013): International Collaboration and Continuous Improvement, Phoenix (USA), vol. 4, WM Symposia Inc., Curran 2013, p. 3243.

[5] J.J. Grenouillet, E. Posivak, in: Waste Management (WM2009) Conf., Tucson, New York (USA), vol. 2, WM Symposia Inc., Curran 2009, p. 847.

[6] A. Loeb, D. Stanke, L. Kemp, in: Waste Management (WM2011) Conf., Tucson, New York (USA), vol. 3, WM Symposia Inc., Curran 2011, p. 2031.

[7] P.E.O. Lainetti, J. Power Energy Eng. 10, 513-521 (2016).

[8] European Commission, "Dismantling Techniques, Decontamination Techniques, Dissemination of Best Practice, Experience and Know-how", Final Report, 2009.

[9] Radiological Safety Fundamental Regulations NSR01, approved according to the CNCAN president order no. 14/24.01.2000 and published in the Romania Official Monitor, Part I no. 404 bis/29.08.2000. 